РОЛЕВЫЕ ОЖИДАНИЯ СТУДЕНЧЕСКОЙ МОЛОДЕЖИ

ОТ СЕМЕЙНОЙ ЖИЗНИ И ПСИХОЛОГИЧЕСКИЕ ОСОБЕННОСТИ ЕЕ УРОВНЕЙ ПРИТЯЗАНИЯ

\author{
ROLE EXPECTATIONS OF STUDENTS ABOUT FAMILY LIFE \\ AND PSYCHOLOGICAL FEATURES OF THEIR LEVELS OF ATTRACTION
}

УДК 159.92

DOI https://doi.org/10.32843/2663 5208.2020 .17 .18

\section{Мусаева Зульфия}

докторант по программе доктора философии по общей психологии Азербайджанский государственный педагогический университет
Mета статmі - вивчення підходів студентської молоді до складності сімейних взаємин, наявності безлічі фракторів, які впливають на ці взаємини та які іноді відіграють вирішальну роль у формуванні їі майбутніх сімейних взаємин, у мотивуванні ії на розвиток гендерного уявлення про сім'ю.

Автор у процесі дослідження використовував такі методи, як науковий аналіз, бесіди, інтерв'ю, обговорення, анкетне опитування й тестування для визначення рольових очікувань студентської молоді в процесі фрормування сімейного життя, а також рівень ї домагань.

Новизною в досліджуваній темі є оригінальний підхід у розумінні взаємин студентської молоді, формування свого майбутнього сімейного життя. Відзначається, що фрормування цих взаємин необ'єктивними оцінками може призвести до дестабілізації в родині, виникнення конорліктів. Із чієї причини автор указує на необхідність урахування питань підготовки студентів до сімейного життя в усіх циклах навчального процесу.

Відзначається, що так як у студентської молоді гендерні ролі в сім'ї й рівень домагань у життєвій ситуації різні, то іноді ці результати можуть не відповідати їі гендерними ролям і життєвим реаліям.

Підкреслюється, що якщо не враховувати виключні особливості, то людина, перебуваючи в утробі матері, уже кодується інформацією, що відповідає статевим особливостям, які до цих пір не розгадані наукою. Відзначається, що зародок уже в утробі матері володіє емоційною ссрерою і рефлексією, специфрічними для своєї cmami, а після народження починає усвідомлювати себе зі статевого погляду. Наголошується, що в психіці кожної людини, загалом у їі існуванні наявна спадкова генетична інформмція і коди. Їх складна комбінація, взаємини в соціальному середовищі й уся їх сукупність формують ії в майбутньому як особистість. Автор підкреслює той фракт, що формування чоловічої й жіночої особистості в студентської молоді відбувається однаково, тому необхіно згадувати, що тут, крім спадкових генетичних характеристик, особливим впливом володіє культурне середовище, що існувало в сім'ї та суспільстві. Особливо важливо з'ясувати, як воно впливає на уми молодих людей і як вони розуміють свої взаємини й роль у майбутньому сімейному житті.

Ключові слова: сприйняття гендерних питань, гендерні відмінності, відносини, конфрлікти, гендерні відмінності, роль очікувань, рівень претензій.
The purpose of the study is to study the approaches of student youth to the complexity of family relationships, the presence of many factors that affect these relationships, and which sometimes play a decisive role of these factors in the formation of their future family relationships in motivating them to develop a gender concept of the family.

In the course of his research, the author used methods such as scientific analysis, conversations, interviews, discussions, questionnaires and testing to determine the role expectations of student youth in the process of forming their family life, as well as the level of their claims.

The novelty in the research topic is the original approach to understanding the relationship of student youth in the formation of their future family life. It is noted that with the biased assessments that formed these relationships, it can lead to destabilization in their family, the emergence of conflicts. For this reason, the author proposes the need to take into account the issues of preparing students for family life in all cycles of the educational process.

It is noted that since the gender roles in the family and the level of aspirations in the life situation are different for student youth, sometimes these results may not correspond to their gender roles and life realities.

It is emphasized that if you do not take into account the exceptional features, then a person being in the womb is already encoded with information corresponding to his sexual characteristics, which has not yet been solved by science. It is noted that the embryo already in the womb has an emotional sphere and reflection specific to its gender. And after birth, he begins to realize himself from a sexual point of view. It is noted that there are hundreds of hereditary genetic information and codes in the psyche of every person, in general, in his existence. Their complex combination, relationships in the social environment and their entire totality forms him in the future as a person. The author emphasizing the fact that the formation of male and female personality in student youth occurs in the same way, it should be noted that here, in addition to hereditary genetic characteristics, the cultural environment that existed in the family and society has a special influence. It is especially important to find out what impression this influence has on the minds of young people and how they understand their relationship and role in future family life.

Key words: gender perceptions, gender differences, relationships, conflict, gender differences, role expectations, level of claims. 
Постановка проблемы. Семейные отношения в психологии изучаются как одна из самых сложных форм межличностных отношений. Исследование в статье также посвящено этой сложной теме - одной из важнейших проблем при подготовке студентов к семейным отношениям. Вопросы, поднятые в статье, связаны с ролевыми ожиданиями в семейных отношениях и уровнем притязаний сторон. Сначала исследователем анализируется характер ролевого поведения как женщин, так и мужчин в разных ситуациях семейной жизни. Показывается, что одним из факторов, создающих напряженность у семейных отношениях, является перенос проблем социальной жизни за пределы этих отношений в семейные отношения. Другая причина - нарушение гендерных ролей. Как известно, в семье обычно происходит разделение труда в зависимости от пола сторон. Когда ролевые ожидания, воспринимаемые как поведенческая модель, нарушаются, в семье возникает напряженность. Чтобы избежать этой напряженности, существуют ролевые модели поведения, как из исторических традиций, так и разработанные исследователями социологии, психологии и педагогики для оптимального регулирования семейных отношений.

Постановка задания. Цель статьи - изучение подходов студенческой молодежи к сложности семейных отношений, наличию множества факторов, которые влияют на эти отношения и которые иногда играют решающую роль в формировании ее будущих семейных отношений, в мотивировании ее на развитие гендерного представления о семье.

Автор в процессе исследования использовал такие методы, как научный анализ, беседы, интервью, обсуждение, анкетный опрос и тестирование, для определения ролевых ожиданий студенческой молодежи в процессе формирования своей семейной жизнью, а также уровень ее притязаний.

Новизной в исследуемой теме является оригинальный подход к пониманию взаимоотношений студенческой молодежью формирования своей будущей семейной жизни. Отмечается, что формирование этих взаимоотношений необъективными оценками может привести к дестабилизации в семье, возникновению конфликтов. По этой причине автор подчеркивает необходимость учитывания вопросов подготовки студентов к семейной жизни во всех циклах учебного процесса.

Изложение основного материала исследования. Таким образом, в теоретической, экономической и политической сферах мужчины, в эстетике, религии и социальных ценностях женщины имеют больше навыков и преимуществ. В этом смысле женщины - настоящие управляющие. В этом смысле женщина является основным человеком, который управляет семьей и регулирует внутрисемейную ситуацию. Поэтому роль женщины в успехе семейной жизни неоспорима. Здесь также подчеркивается своеобразная роль мужчины в семье, которая оценивается с этнокультурной точки зрения. На основе подходов ряда исследователей обобщаются мнения о роли «мужчина-женщина», «отец-мать». Причины ролевых конфликтов выдвигаются на первый план. Указаны задачи, стоящие перед сторонами по их устранению. Помимо теоретических подходов к проблеме, материалы, представленные в статье, изучают представления студентов об их роли в будущей семье и уровне притязаний, а также делают выводы. Показывается, что из-за половых особенностей существуют значительные различия в гендерных представлениях мальчиков и девочек. Так, среди девочек есть те, у которых ролевые ожидания и уровень притязаний намного больше. Эмоциональная оценка их уровней притязания превышает мальчиков. Это указывает на то, что у них более романтичный подход к семейным отношениям. У мальчиков преобладают ролевые ожидания по внешности девочек. Для этого в статье подчеркивается, что для студенческой молодежи при подготовке к семейной жизни важно знать особенности, вкусы и интересы, оценки и требования стороны, с которой планируется брак.

Студенческая молодежь должна понимать, что от нее зависит стабильное и устойчивое будущее государства и общества, а также влияние прочной семейной основы на духовное здоровье общества. Поэтому подготовка студенческой молодежи к семейной жизни, формирование чувства ответственности при вступлении в семейно-брачные отношения и взаимопонимания как актуальная проблема должны учитываться в воспитательной работе, проводимой в высших учебных заведениях, у них надо формировать ответственный подход к семейным отношениям. Семья, брачные отношения и добровольное согласие женщины и мужчины жить вместе являются основными факторами, определяющими силу семьи. Именно правильное понимание и формирование чувства ответственности гарантирует успешную семейную жизнь молодежи в будущем. При создании положительной среды в семье позитивные отношения основаны на двух основных понятиях: ролевом поведении и адаптации. Здесь ключевым моментом является выбор правильной формы поведения в нужное время, то есть своевременность поведения. И мужчины, и женщины должны быть в состоянии достичь этого баланса. Это требует особой заботы и внимания с обеих сторон. Например, если мужчина приходит домой с работы очень уставшим и напряженным и женщина хочет обсудить с ним любую проблему, он, скорее всего, отреагирует отрицательно. Это потому, что поведение женщины 
неуместно и может привести к неудаче. Такая неуместная реакция создает негативную атмосферу в отношениях и приводит к конфликту. Поэтому женщинам нужно быть более понятливыми в этих вопросах.

Такая же ситуация может произойти и на другой стороне. В целом мужчины более нетерпимы и неустойчивы к проблемам, с которыми они сталкиваются в своей трудовой жизни. Они часто несут проблемы вне семьи к своим семьям. Следовательно, и мужчины, и женщины для того, чтобы защитить свои семьи от конфликтов, не должны переносить их в свои семьи. В этом смысле такие важные вопросы должны быть доведены до сведения студенческой молодежи.

Одним из факторов, способствующих конфликту в семье, является нарушение баланса в выполнении гендерных ролей. Так, в семье разделение обязанностей осуществляется в соответствии с полом сторон. Распределение обязанностей по гендерным ролям основано на древней исторической традиции. В результате такого образа жизни, который воспринимается как модель, когда ролевые ожидания нарушаются, в семье возникает напряженность. Следует также отметить, что, в наше время, поскольку традиционные гендерные роли изменились в лучшую сторону, ролевые ожидания в этом отношении также изменились, поэтому конфликтные ситуации приобрели новое значение.

Рост числа разводов в последние годы привел к свободному образу жизни, внебрачным отношениям и рождению детей вне брака, увеличению числа одиноких родителей и другим проблемам. Повышение в людях эго привело кжеланию жить лучше. Р.И. Алиев происходящие события связывает с нижеследующим: «История Азербайджана, происхождение, этноген, быт, традиции азербайджанцев зависели от политической атмосферы. Мы располагаемся в таком месте, где, с одной стороны, Запад, а с другой, Восток сливаются. Итак, каждый из них отражается в нашей психологии с ее положительными и отрицательными оттенками» [1, с. 172].

В последние годы этой проблеме уделено особое внимание. Объясняя гендерную психологию как новое научное направление, Ж.Г. Душказиева подчеркивает важность психологического подхода к решению гендерных проблем [2]. Привлекают внимания подходы Г.В. Вержибака [3], И.И. Сиркуна [4)] и других относительно особенностей гендерных стереотипов студенческой молодежи, гендерных аспектов подготовки студенческой молодежи к осознанному воспитанию детей и родительству. Аналогичны исследования Э.И. Лилиенталя [5] и других. Конечно, мужчины играют своеобразную роль в семье. В азербайджанской культуре в этой области сформированы богатые ролевые модели поведения. В связи с этим А.А. Ализаде пишет: «Образ мужчины в народе был велик. Его рвение считалось не только честью семьи, поколения или племени, но и честью деревни. Мужчине доверяют. Велико влияние мужского слова» [6, с. 141].

А.С. Байрамов характеризует роль мужчины в семье многими преимуществами: «У огузов отец - умелый глава семьи и прекрасный воспитатель. Власть отца в семье основана на личных качествах, не носит деспотичный характер. Взаимная искренность, уважение к старшим и женщинам играют важную роль в семейных отношениях. Отец стремится к тому, чтобы его сын вырос сильным человеком и достойным наследником» [7, с. 47].

Р.О. Мамедова связывает причины отклонений и недопонимания во взаимоотношениях женщины (матери) и мужчины (отца) в семье с поведенческими и ролевыми конфликтами. В обоих случаях личность показывает, что источник внутреннего конфликта скрыт. «В результате конфликта с различными ролевыми позициями личности возникают ролевые конфликты в следующих областях» [8, с. 16]:

1) трудности в выполнении традиционных социальных ролей в семье;

2) неспособность выполнять несколько ролей (родитель, профессионал, друг и т. д.) одновременно;

3) ослабление чувства времени, нехватка времени;

4) изменения в оценке социальных ролей;

5) потеря межролевой связи;

6) ослабление необходимости выполнять свою работу на высоком уровне.

Одним из наиболее важных вопросов в гендерных представлениях студентов является их уровень притязания в отношении ролевого ожидания другой стороны. «Требование является ценным аспектом личности и объединяет представления о том, как удовлетворить жизненные потребности.

Другими словами, оничетко определяют природу внутренних импульсов, обуславливающих самоуправление: комфорт, сложность, удовлетворенность. Такой смысловой интеграл - это не абстрактная целостная структура, а реальное гармоничное или противоречиво деформированное и акцентуационное состояние личности. Эта ситуация проявляется в положительных и отрицательных последствиях образа жизни человека» [9, с. 182].

Чтобы выяснить отношение студентов к этим вопросам, мы провели десятки опросов. Проанализировали результаты опросов, сгруппировав их отдельно по мальчикам и девочкам. Эти опросы с участием 93 девочек и 79 мальчиков позволили нам сделать некоторые выводы. Так, согласно эмоциональному содержанию ролевого ожидания 93 девушек о гендерном восприятии, 54\% имеют высокие ожидания и высокие притязания. Те, у кого ожидания высоки, 
а притязания низки, составляют 13\%. Ожидания и притязания низкие, а также низкие ожидания и высокие требования у 1\%, а те, чьи ожидания и претензии совпадают, составляют 30\%
Согласно эмоциональному содержанию ролевых ожиданий 79 мальчиков в гендерном восприятии, 32\% имеют высокие ожидания и притязания. У $19 \%$ ожидания высоки, а притязания низки.

\section{Ролевые ожидания и уровень притязаний по семейным ценностям} в гендерном восприятии студентов

\begin{tabular}{|c|c|c|c|c|c|c|c|c|c|c|c|}
\hline \multirow{2}{*}{ S.S } & \multirow{2}{*}{\begin{tabular}{|c} 
Взгляды \\
Статистические \\
критерии
\end{tabular}} & \multicolumn{2}{|c|}{$\begin{array}{c}\text { Ожидания } \\
\text { высоки, } \\
\text { притязания } \\
\text { высоки } \\
\end{array}$} & \multicolumn{2}{|c|}{$\begin{array}{c}\text { Ожидания } \\
\text { высоки, притя- } \\
\text { зания низки }\end{array}$} & \multicolumn{2}{|c|}{$\begin{array}{c}\text { Ожидания } \\
\text { низки, притя- } \\
\text { зания низки }\end{array}$} & \multicolumn{2}{|c|}{$\begin{array}{c}\text { Ожидания } \\
\text { низки, притя- } \\
\text { зания высоки }\end{array}$} & \multicolumn{2}{|c|}{$\begin{array}{c}\text { Ожидания и } \\
\text { притязания } \\
\text { совпадают }\end{array}$} \\
\hline & & чел. & $\%$ & чел. & $\%$ & чел. & $\%$ & чел. & $\%$ & чел. & $\%$ \\
\hline \multirow[t]{3}{*}{1 a. } & \multirow{3}{*}{$\begin{array}{l}\text { Ролевые ожидания } \\
\text { и уровень притя- } \\
\text { заний девочек по } \\
\text { семейным ценно- } \\
\text { стям - } 93 \\
\end{array}$} & 27 & $29 \%$ & 36 & $39 \%$ & 6 & $6 \%$ & 7 & $8 \%$ & 17 & $18 \%$ \\
\hline & & \multicolumn{8}{|c|}{ Нет ожиданий } & 0 & $0 \%$ \\
\hline & & \multicolumn{8}{|c|}{ Нет притязаний } & 8 & $9 \%$ \\
\hline \multirow[t]{3}{*}{$1 \mathrm{~b}}$. & \multirow{3}{*}{$\begin{array}{l}\text { Ролевые ожидания } \\
\text { и уровень притяза- } \\
\text { ний мальчиков по } \\
\text { семейным ценно- } \\
\text { стям - } 79 \\
\end{array}$} & 12 & $15 \%$ & 23 & $29 \%$ & 22 & $27 \%$ & 13 & $17 \%$ & 9 & $12 \%$ \\
\hline & & \multicolumn{8}{|c|}{ Нет ожиданий } & 5 & $6 \%$ \\
\hline & & \multicolumn{8}{|c|}{ Нет притязаний } & 9 & $11 \%$ \\
\hline \multirow[t]{3}{*}{2 a. } & \multirow{3}{*}{$\begin{array}{l}\text { Ролевые ожидания } \\
\text { и уровень притяза- } \\
\text { ний девочек в семье } \\
\text { по социальной } \\
\text { активности -93 } \\
\end{array}$} & 38 & $41 \%$ & 15 & $16 \%$ & 4 & $4 \%$ & 11 & $12 \%$ & 25 & $27 \%$ \\
\hline & & \multicolumn{8}{|c|}{ Нет ожиданий } & 0 & $0 \%$ \\
\hline & & \multicolumn{8}{|c|}{ Нет притязаний } & 5 & $5 \%$ \\
\hline \multirow[t]{3}{*}{2 b. } & \multirow{3}{*}{$\begin{array}{l}\text { Ролевые ожидания и } \\
\text { уровень притязаний } \\
\text { девочек в семье по } \\
\text { социальной актив- } \\
\text { ности - } 79\end{array}$} & 9 & $11 \%$ & 8 & $10 \%$ & 15 & $19 \%$ & 10 & $13 \%$ & 37 & $46 \%$ \\
\hline & & \multicolumn{8}{|c|}{ Нет ожиданий } & 4 & $5 \%$ \\
\hline & & \multicolumn{8}{|c|}{ Нет притязаний } & 11 & $14 \%$ \\
\hline
\end{tabular}

Ожидания и уровень притязаний низкие у $6 \%$, а также ожидания низки, а требования высоки у $1 \%$, ожидания и притязания совпадают у $25 \%$.
Теперь посмотрим на различия в оценках студентами эмоционального содержания ролевого ожидания и внешнего вида.

Таблица 2

\section{Социально-эмоциональное содержание ролевого ожидания студентов в гендерном восприятии}

\begin{tabular}{|c|c|c|c|c|c|c|c|c|c|c|c|}
\hline S.S & Взгляды & \multicolumn{2}{|c|}{$\begin{array}{c}\text { Ожидания } \\
\text { высоки, притя- } \\
\text { зания высоки }\end{array}$} & \multicolumn{2}{|c|}{$\begin{array}{c}\text { Ожидания } \\
\text { высоки, притя- } \\
\text { зания низки }\end{array}$} & \multicolumn{2}{|c|}{$\begin{array}{c}\text { Ожидания } \\
\text { низки, притя- } \\
\text { зания низки }\end{array}$} & \multicolumn{2}{|c|}{$\begin{array}{c}\text { Ожидания } \\
\text { низки, притя- } \\
\text { зания высоки }\end{array}$} & \multicolumn{2}{|c|}{$\begin{array}{c}\text { Ожидания и } \\
\text { притязания } \\
\text { совпадают }\end{array}$} \\
\hline \multicolumn{2}{|c|}{ Статистические взгляды } & чел. & $\%$ & чел. & $\%$ & чел. & $\%$ & чел. & $\%$ & чел. & $\%$ \\
\hline \multirow[t]{3}{*}{$1 \mathrm{a}}$. & \multirow{3}{*}{$\begin{array}{l}\text { Эмоциональное } \\
\text { содержание роле- } \\
\text { вых ожиданий дево- } \\
\text { чек в гендерном } \\
\text { восприятии - } 93\end{array}$} & 51 & $54 \%$ & 12 & $13 \%$ & 1 & $1 \%$ & 1 & $1 \%$ & 28 & $30 \%$ \\
\hline & & \multicolumn{8}{|c|}{ Нет ожиданий } & 1 & $1 \%$ \\
\hline & & \multicolumn{8}{|c|}{ Нет притязаний } & 1 & $1 \%$ \\
\hline \multirow[t]{3}{*}{$1 \mathrm{~b}}$. & \multirow{3}{*}{$\begin{array}{l}\text { Эмоциональное } \\
\text { содержание роле- } \\
\text { вых ожиданий } \\
\text { мальчиков в гендер- } \\
\text { ном восприя-тии -79 }\end{array}$} & 25 & $32 \%$ & 15 & $19 \%$ & 2 & $6 \%$ & 1 & $1 \%$ & 20 & $25 \%$ \\
\hline & & \multicolumn{8}{|c|}{ Нет ожиданий } & 5 & $6 \%$ \\
\hline & & \multicolumn{8}{|c|}{ Нет притязаний } & 7 & $9 \%$ \\
\hline \multirow[t]{3}{*}{2 a. } & \multirow{3}{*}{$\begin{array}{l}\text { Ролевые ожида-ния } \\
\text { девочек по внеш- } \\
\text { нему виду - } 93\end{array}$} & 26 & $27 \%$ & 17 & $18 \%$ & 11 & $12 \%$ & 18 & $17 \%$ & 21 & $26 \%$ \\
\hline & & \multicolumn{8}{|c|}{ Нет ожиданий } & 4 & $4 \%$ \\
\hline & & \multicolumn{8}{|c|}{ Нет притязаний } & 12 & $13 \%$ \\
\hline \multirow[t]{3}{*}{$2 \mathrm{~b}}$. & \multirow{3}{*}{$\begin{array}{l}\text { Ролевые ожидания } \\
\text { мальчиков по внеш- } \\
\text { нему виду - } 79\end{array}$} & 15 & $19 \%$ & 18 & $23 \%$ & 17 & $22 \%$ & 10 & $13 \%$ & 19 & $23 \%$ \\
\hline & & \multicolumn{8}{|c|}{ Нет ожиданий } & 2 & $3 \%$ \\
\hline & & \multicolumn{8}{|c|}{ Нет притязаний } & 14 & $18 \%$ \\
\hline
\end{tabular}


Посмотрим на различия здесь в статистических описаниях. Рассмотрим эти изображе- ния на рисунках. Эти различия мы ясно сможем увидеть в нижеследующих рисунках.

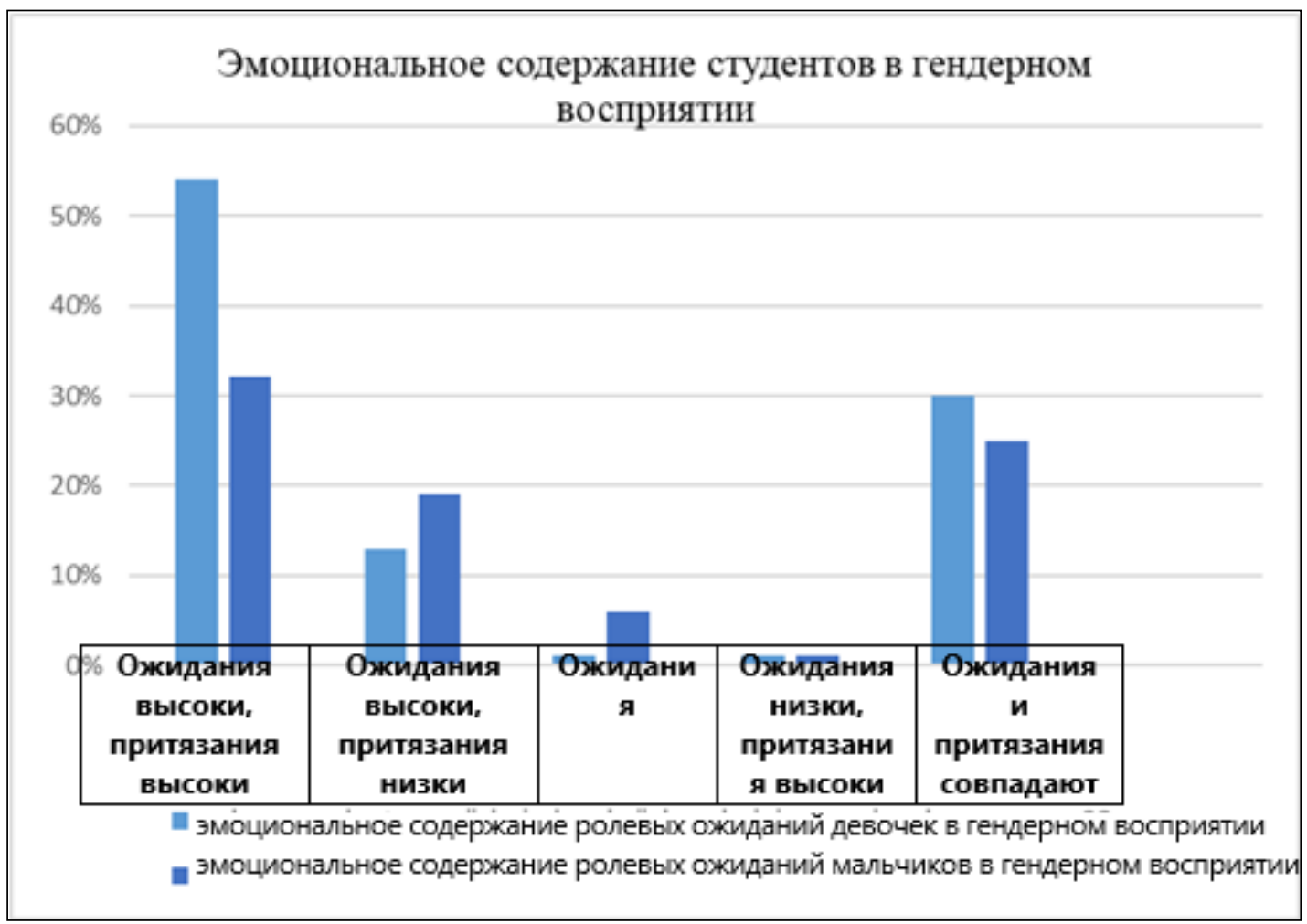

Рис. 1. Ролевые ожидания мальчиков и девочек по внешнему виду

На рисунке 1 мы не видим гендерные различия между девочками и мальчиками. Видно, что ожидания у девочек, как правило, высоки, а у мальчиков - низки. Рассматривая эти притязания у девочек, мы сталкиваемся с интересной картиной. Те, у кого ожидания и притязания низки, составляют $12 \%$, ожидания низки, а притязания высоки $-17 \%$, ожидания и притязания совпадают - 26\%. Процентный показатель у девочек, у которых есть противоречия между ожиданием и уровнем притязания, низок, около 1\%. Это, конечно, показывает стабильность их эмоциональной сферы. Среди девочек много тех, у кого ожидания и притязания высоки. Это говорит об их высокой самоуверенности. У $27 \%$ девочек ролевые ожидания и притязания по внешнему виду высоки, а у 18\% - ожидания высоки, а притязания - низки.

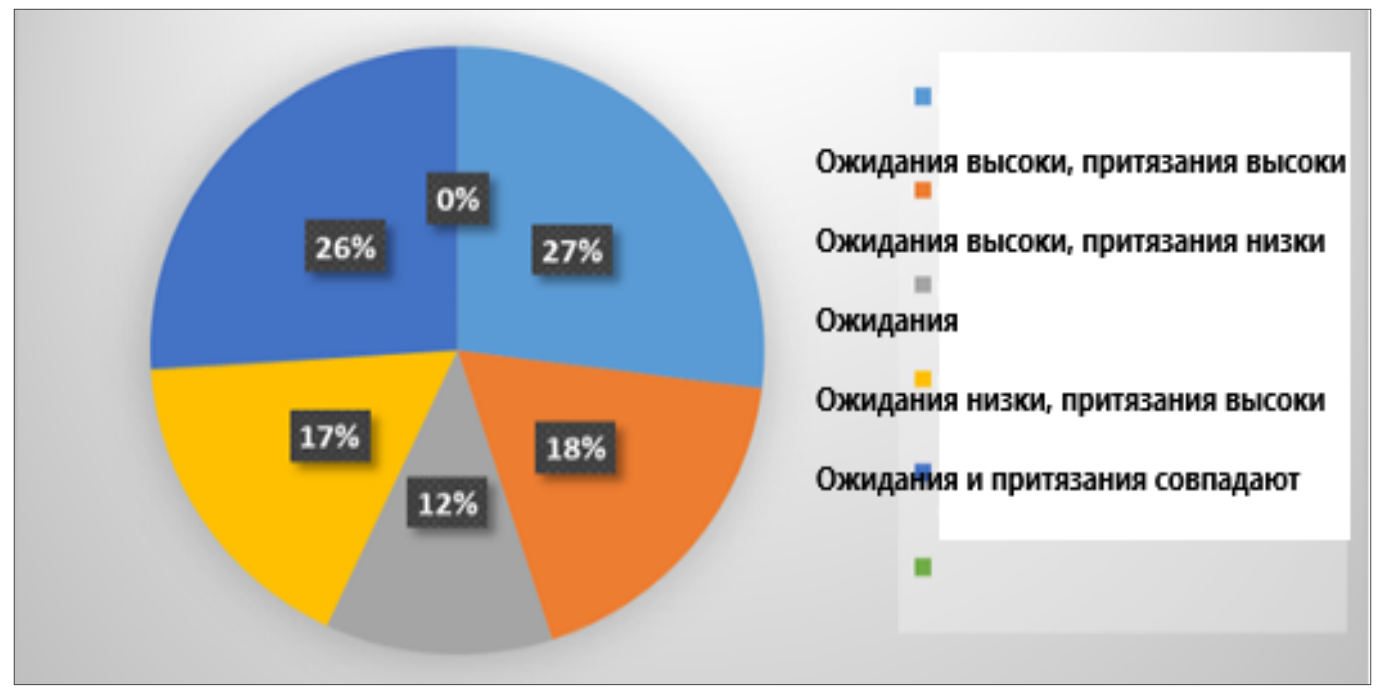

Рис. 2. Ролевые ожидания девочек по внешнему виду 
У мальчиков также преобладают ролевые ожидания по внешности. У 19\% ожидания и притязания велики, у 23\% - ожидания велики, притязания низки, а у $22 \%$ - ожидания и притязания низки, у $13 \%$ - ожидания низки, притязания велики, у 23\% - ожидания и притязания совпадают.

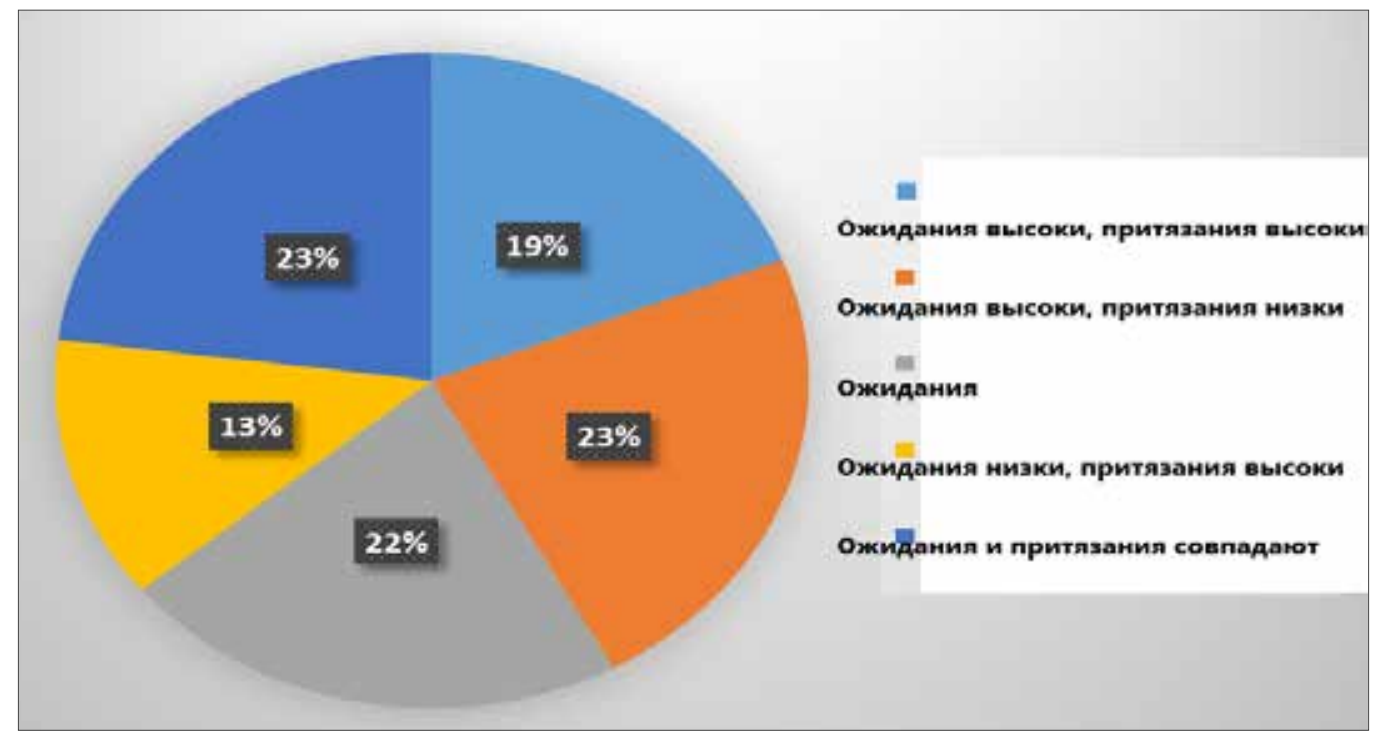

Рис. 3. Ролевые ожидания мальчиков по внешности

Как видно, существуют значительные различия в гендерном восприятии девочек и мальчиков. Эти различия связаны не только с индивидуальными особенностями их личности, но и с их половыми характеристиками. Исследование еще раз показывает, что по этой причине учет гендерных различий студентов в исследовании является важным психологическим фактором. Рассматривая с этой точки зрения, важно подготовить учащихся к семейной жизни, сформировать чувство ответственности и взаимопонимания при вступлении в семейно-брачные отношения. Для этого студентам важно знать особенности, вкусы и интересы стороны, с которой они собираются вступать в брак, а также оценку и уровень притязаний. В этом направлении должна вестись воспитательная работа. Программы и учебники должны объяснять природу семейно-брачных отношений и ответственность семьи перед обществом. Студенты и молодежь должны понимать, что от них зависит успешное будущее государства и общества. Именно правильное понимание и формирование чувства ответственности гарантирует успешную семейную жизнь молодежи в будущем. Семья, супружеские отношения, добровольное согласие женщины и мужчины на совместное проживание являются ключевым фактором прочности семьи. Информированность студентов по этой теме - один из важнейших вопросов воспитательной работы.
Выводы из проведенного исследования. Отмечается, что, так как у студенческой молодежи гендерные роли в семье и уровень притязаний в жизненной ситуации различны, иногда эти результаты могут не соответствовать их гендерным ролям и жизненным реалиям.

Подчеркивается, что если не учитывать исключительные особенности, то человек, находясь в утробе матери, уже кодируется информацией, соответствующей своей половой особенности, которая до сих пор не разгадана наукой. Отмечается, что зародыш уже в утробе матери обладает эмоциональной сферой и рефлексией, специфичными для своего пола, а после рождения начинает осознавать себя с половой точки зрения. Отмечается, что в психике каждого человека, в целом в его существовании присутствует наследственная генетическая информация и коды. Их сложная комбинация, взаимоотношения в социальной среде и вся их совокупность формируют его в будущем как личность. Автор подчеркивает тот факт, что формирование мужской и женской личности в студенческой молодежи происходит одинаково, поэтому необходимо упоминать, что, помимо наследственных генетических характеристик, особым влиянием обладает культурная среда, существовавшая в семье и обществе. Особенно важно выяснить, какое влияние она оказывает на умы молодых людей и как они понимают свои взаимоотношения и роль в будущей семейной жизни. 


\section{ЛИТЕРАТУРА:}

1. əliyev R.i. Mentalitet. Bakı : Elm və Təhsil, 2009. $232 \mathrm{~s}$.

2. Дусказиева Ж.Г. Гендерная психология. Красноярск : Гос. пед. ун-т, 2010. 108 с.

3. Вержибок Г.В. Из практики гендерного образования студенческой молодежи. Ученые записки. 2009. № 3-4. Т. 2 : Психология. Педагогика. С. 52-56.

4. Цыркун И.И. Гендерные аспекты подготовки студенческой молодежи к осознанному родительству и воспитанию детей в свете национального плана действий по обеспечению гендерного равенства. Материалы Международной конореренции, 7-8 апреля 2011 г. Минск : Изд. центр БГУ, 2011. C. $136-141$.
5. Лилиенталь И.Е. Психологическая поддержка студентов в период адаптации к образовательному процессу в вузе : автореф. дисс. ... канд. психол. наук. Ставрополь, 2000, 20 с.

6. Әlizadə Ә.ə. Azərbaycan etnopsixologiyasına giriş. Bakı : Renessans, 2003. $258 \mathrm{~s}$.

7. Bayramov ə.S. "Kitabi-Dədə Qorqud" dastanlarında etnik-psixoloji xüsusiyyətlərin inikası. Bakı : Nurlan, 2000. $145 \mathrm{~s}$.

8. Məmmədova R.O. Ailədaxili münaqişələrin kiçikyaşı məktəblilərin psixi inkişafına təsiri // psixol. elm üzrə fəl. dok. diss... Bakı, 2017. 153 s.

9. Әmrahlı L.Ş. Şəxsiyyət və cəmiyyət. Bakı : MBM, 2007, 200 s. 